\title{
EDUCAÇÃO EM SOLOS NO MACIÇO DE BATURITÉ: EXPERIÊNCIA COM ALUNOS DO ENSINO FUNDAMENTAL
}

\author{
Rosemery Alesandra Firmino dos Santos ${ }^{1}$, Susana Churka Blum², Smaiello Flores da Conceição \\ Borges dos Santos ${ }^{3}$, Stallone da Costa Soares ${ }^{4}$, Edvaldo Renner da Costa Cardoso ${ }^{5}$, Elisia Gomes \\ Ramos $^{6}$, Daniela Queiroz Zuliani ${ }^{7}$
}

\begin{abstract}
RESUMO - O objetivo deste trabalho foi verificar o conhecimento sobre tema solo com alunos do ensino fundamental, realizar uma ação de extensão através projeto intitulado Educação em solos no Maciço de Baturité e avaliar o progresso dos estudantes a respeito do tema solo após a atividade. O trabalho foi realizado com alunos do $4^{\circ}$ ano da escola da rede pública de ensino Edmilson Barros de Oliveira, localizada no Município de Redenção, Estado do Ceará. A atividade consistiu em uma parte teórica, onde foram trabalhados temas relacionados ao solo como a importância do solo, formação do solo, seus constituintes e suas características e as ações que levam a degradação do solo. Para melhor compreensão dos alunos, trabalhou-se também com experimentos de infiltração de água no solo, montagem de perfil do solo, sequência de formação do solo e erosão do solo. Os alunos foram avaliados antes e após a atividade por meio de utilização de questionários, com cinco questões. Os resultados demonstraram que antes da atividade os alunos tinham uma visão muito básica do solo, com problemas em identificar a sua importância, seus constituintes e sua formação. Após a atividade, verificou-se que os alunos aumentaram o nível de conhecimento em relação aos assuntos tratados. A utilização da experimentação foi fundamental para participação dos alunos e no entendimento do que foi falado. Com isso, pode-se concluir que a educação em solos com a sua proposta metodológica, principalmente prática contribui para melhoria do ensino de solos nas escolas.
\end{abstract}

Palavras chave: ciência do solo, educação ambiental, ensino do solo, experimentação.

\section{SOIL EDUCATION AT MACIÇO OF BATURITÉ: EXPERIENCE WITH STUDENTS OF ELEMENTARY SCHOOL}

\begin{abstract}
The objective of this work was to verify the knowledge on soil theme with elementary school students, to carry out an extension action through a project titled Education on Soils in the Baturité Maciço and to evaluate the students' progress regarding the soil theme after the activity. The work was carried out with students from the 4th grade of the public school Edmilson Barros de Oliveira, located in the Municipality of Redenção, State of Ceará. The activity consisted of a theoretical part, where soil related topics such as soil importance, soil formation, its constituents and characteristics and actions leading to soil degradation were worked. To better understand the students, we also worked with soil infiltration experiments, soil profile assemblage, soil formation sequence and soil erosion. The students were evaluated before and after the activity through the use of questionnaires, with five questions. The results showed that before the activity students
\end{abstract}

\footnotetext{
${ }^{1}$ Mestranda em solos e nutrição de plantas, Universidade Federal de Viçosa/UFV, Email:rosesantos1993@hotmail.com

${ }^{2}$ Professora do Instituto de Desenvolvimento Rural da Universidade da Integração Internacional da Lusofonia Afro-brasileira/ UNILAB, Email:scblum@unilab.edu.br

${ }_{3}^{3}$ Mestrando em Agricultura Tropical, Universidade Federal do Piauí/UFPI, Email:mazyfcp1@hotmail.com

${ }^{4}$ Mestrando em ciência do solo, Universidade Federal do Paraná/UFPR, Email:stallonesoares@hotmail.com

${ }^{5}$ Mestrando em ciência do solo, Universidade Federal do Paraná/UFPR, Email:edvaldorcardoso@hotmail.com

${ }^{6}$ Mestranda em solos e nutrição de plantas, Universidade Federal de Viçosa/UFV, Email:1isyramos16@hotmail.com

${ }^{7}$ Professora do Instituto de desenvolvimento rural da Universidade da Integração Internacional da Lusofonia Afro-brasileira/ UNILAB, Email:danielaqzuliani@unilab.edu.br
} 


\begin{abstract}
had a very basic view of the soil, with problems in identifying its importance, its constituents and its formation. After the activity, it was verified that the students increased the level of knowledge regarding the subjects treated. The use of experimentation was fundamental for student participation and understanding of what was said. With this, it can be concluded that soil education with its methodological proposal, mainly practical, contributes to the improvement of soil education in schools.
\end{abstract}

Keywords: environmental education, experimentation, soil science, teaching of the soil.

\section{INTRODUÇÃO}

A degradação ambiental tem sido bastante debatida e colocada em evidência, principalmente quando se fala da água, do ar e da biodiversidade. Entretanto, o solo enquanto componente do ecossistema aparece pouco mencionado, necessitando assim dar ênfase ao solo também como parte integrante do ambiente e de sua relação com os demais componentes (Frasson \& Werlang, 2010).

O solo é um recurso vital, não renovável na escala humana, e que está cada vez mais sob pressão antrópica, o que representa um risco para a continuidade de nossa sociedade (Pérez et al., 2016). A degradação desse recurso natural, bem como seu esquecimento pela sociedade pode ser explicada pela forma como o tema é tratado nos espaços de ensino formal, mesmo este estando presente nos Parâmetros Curriculares Nacionais (PCN) em séries do ensino fundamental e médio associado às disciplinas de geografia, ciências e biologia (Oliveira, 2017). Necessita-se, porém de sua inclusão nos temas transversais do meio ambiente, tratando os solos numa perspectiva integral que abarque todos os elementos da natureza e sua relações (Frasson \& Werlang, 2010).

Para Lima (2004) a pouca valorização do solo como componente do ambiente natural e antrópico no ensino fundamental e médio, pode ser explicado por diversas variáveis que afetam o processo de ensino, como o senso comum que o aluno traz de seu ambiente familiar e social, os livros didáticos, a formação de docentes, os currículos escolares, a estrutura da escola e o meio no qual essa se insere.

A abordagem trazida pelos livros didáticos e a formação de docentes são as causas mais apontadas em trabalhos para ausência ou pouca representatividade do tema solo no ensino fundamental. De acordo com Biondi (2008) o tema exige dos professores uma visão holística, multi e interdisciplinar para que o aluno não veja o ambiente compartimentalizado e compreenda a importância de cada componente da natureza para a sustentabilidade do planeta. Quanto aos materiais didáticos, estes apresentam falhas, informações tecnicamente incorretas e muitas vezes inadequadas à realidade brasileira (Falcão \& Sobrinho, 2014). Há também a visão do solo somente do ponto de vista econômico, não havendo relação com sua origem, formação, potencialidades, nova classificação, problemas e conservação (Oliveira, 2014).

A conscientização necessária à preservação do solo, enquanto constituinte da paisagem e base de grande parte da vida existente no planeta, pode ser adquirida na escola por meio de atividades que visem a identificação de atributos, características e diferentes formas de utilização, de modo que o solo passe a fazer parte do imaginário e da realidade cognitiva do educando (Jesus, 2013). A Educação em solos, termo sugerido por Muggler et al. (2006) ao invés de ensino de solos, constitui-se ferramenta importante para a conscientização pedológica.

Os projetos de extensão em educação em solos podem ser uma alternativa para suprir as lacunas referentes ao ensino de solos no ensino básico, englobando alunos e professores de escolas da rede pública e privada de ensino. E o mais importante, é que as ações de extensão tragam algo de diferente do adotado no ensino formal, como utilização de materiais didáticos que aproximem o educando do tema, da sua relação com os outros componentes do ambiente e com sua realidade.

Desta forma, este trabalho teve como objetivo verificar a compreensão do tema solo, de estudantes do ensino fundamental antes e após a ação de extensão realizada pelo projeto intitulado Educação em solos no Maciço de Baturité, no município de Redenção, Estado do Ceará.

\section{MATERIAL E MÉTODOS}

O presente trabalho foi fruto de uma ação realizada no âmbito do Projeto de extensão em educação em solos 
no Maciço de Baturité, no município de Redenção. O referido município está localizado no Estado do Ceará, distando $60 \mathrm{Km}$ da capital, Fortaleza. A ação foi realizada na Escola Edmilson Barros de Oliveira, com 22 alunos do $4^{\circ}$ ano do ensino fundamental, com idades compreendidas entre 9 a 11 anos.

Num primeiro momento, foi realizada uma explanação oral por meio de contação da história utilizando imagens como apoio, onde foram abordados os seguintes assuntos: a importância do solo, sua origem e formação, suas características físicas e a degradação do solo.

Após a explanação, foi realizado experimentos com a participação dos alunos. Os experimentos trabalhados foram: erosão hídrica, formação do solo, perfil do solo e infiltração de água no solo. Para elaboração dos experimentos, a experimentoteca de solos do projeto solo na escola do Departamento de Solos e Engenharia Agrícola da Universidade Federal do Paraná (UFPR) foi utilizada como apoio.

O experimento para exemplificação da erosão do solo, consistiu no preenchimento de duas garrafas pet com solo, onde em uma delas havia solo com cobertura vegetal e outra sem proteção da vegetação. Com a simulação da chuva a água escorria sobre o solo e caía em um recipiente localizado na extremidade da garrafa pet. A água que escoava pela garrafa com cobertura vegetal apresentava-se límpida, enquanto a que escoava pela garrafa que continha somente o solo apresentava-se carregada de partículas de solo. Com o experimento, instigou-se os alunos a responderem a razão pela qual um dos recipientes apresentava água de coloração mais escura. Dessa forma, foi discutida a erosão hídrica do solo e a importância da cobertura vegetal para conservação do solo e da água.

O experimento sobre formação do solo foi realizado em três garrafas pet cortadas na parte superior, em seguida foi montada a sequência de formação do solo, colocando no primeiro recipiente a rocha e o início de sua degradação, no segundo a rocha e o aparecimento do primeiro horizonte do solo com suporte da vegetação e no terceiro um solo já mais desenvolvido com vários horizontes. Com o solo formado no terceiro recipiente discutiu-se sobre o conceito de perfil do solo e de horizontes, as camadas do solo formadas a partir de processos pedogenéticos. Essa dinâmica serviu também de base para trabalhar com as cores do solo, pois os horizontes do solo apresentam colorações diferentes.
O experimento sobre infiltração de água no solo foi constituído também por duas garrafas pet cortadas na parte superior e a mesma parte superior da garrafa colocada em formato de um funil encaixado na extremidade cortada. Foram colocados dois solos de textura diferente em cada recipiente, e adicionou-se a mesma quantidade de água ao mesmo tempo nos dois recipientes. Foi verificado com a ajuda dos alunos, o tempo e a quantidade de água que começou a pingar na garrafa, para os dois solos. Esse experimento serviu de base para trabalhar os componentes do solo, argila, silte, areia e matéria orgânica, bem como a textura e a porosidade do solo.

Os materiais utilizados foram previamente preparados utilizando materiais simples, reciclados e facilmente encontrados, podendo ser reproduzidos pelos professores.

Com o intuito de avaliar o conhecimento dos alunos e a efetividade da ação, foi aplicado um questionário antes e após a atividade, e as perguntas foram respondidas com apenas uma palavra. O questionário foi composto por cinco questões com poucas diferenças entre o aplicado antes e após a atividade. O questionário aplicado antes do início da atividade englobava as seguintes questões: 1 - O solo vem da ....?; 2- O solo serve para....?; 3- No solo tem...?, 4- Já estudou sobre o solo?; 6- O solo tem a cor?. Após a atividade a questão 4 foi modificada, 4- O solo é destruído por? e foi acrescentada mais uma questão: 7-O que você mais gostou de aprender sobre o solo?

As respostas dos questionários foram analisadas segundo o método de análise de contéudos de Bardin (2011). O método consiste em categorizar as respostas buscando identificar as frequências ou ausências de itens que caraterizam o conhecimento do aluno sobre o tema da questão buscando obter uma ordem nos dados.

Com os resultados obtidos foram elaborados gráficos para cada questão antes e após a realização da ação, com a utilização do Excel, sendo os valores expressos em porcentagem.

\section{RESULTADOS E DISCUSSÃO}

Os resultados obtidos através da aplicação do questionário antes da realização das atividades revelaram que, em geral, os alunos apresentavam pouca ou nenhuma informação sobre o solo. Este recurso estava relacionado com o plantio, não havendo o entendimento 
de seu modo de formação, sua composição e as diferenças entre os tipos de solos.

Verificou-se que $81,8 \%$ da turma relaciona a origem do solo com a terra (terra como o nome utilizado cotidianamente para o solo não com o planeta terra), antes da atividade, como mostra a Figura 1 A. Com a atividade os alunos conseguiram entender que o solo é formado a partir da rocha, visto que as repostas revelaram que $81,8 \%$ dos estudantes utilizou essa palavra para associar a origem do solo (Figura 1B).

Ribeiro e Macêdo (2016) avaliando o conhecimento prévio dos alunos do $6^{\circ}$ ano do ensino fundamental da zona rural do Cariri cearense verificaram que os alunos desconheciam a origem do solo, sendo citado pelos alunos que o solo era construído pelo homem, que o solo vem da terra, que o solo nasce da água, da natureza, dos animais.

Canapelle et al. (2018), antes da realização de atividades práticas e teóricas com alunos do $8^{\circ} \mathrm{e}$ $9^{\circ}$ ano do ensino fundamental e $3^{\circ}$ ano do ensino médio, observaram que a grande maioria dos estudantes não possuíam conhecimento sobre o conceito de solo (80\%), respondendo incorretamente quando questionados sobre o conceito de solo, e apenas $16 \%$ responderam corretamente. Quanto à origem do solo, os autores verificaram que a maioria dos estudantes não possui conhecimento sobre Pedologia, pois apenas 7\% dos analisados atribuíram a formação do solo com o intemperismo das rochas; já $93 \%$ dos estudantes consideraram que o solo provinha da decomposição de plantas ou da ação do homem.
Freitas et al. (2018) aplicaram questionários para avaliar o conhecimento prévio de alunos do $5^{\circ}$ ano do ensino fundamental e quando questionados sobre conceito de solo, $26 \%$ responderam que se trata do chão, enquanto que aproximadamente $24 \%$ responderam que o solo trata-se da terra, $8 \%$ identificaram o solo como terra e chão, $18 \%$ não souberam responder e $10 \%$ e $14 \%$ associaram a palavra solo ao Sol (Corpo celeste que apresenta luz própria) e a elementos da natureza, respectivamente.

Quanto à utilização do solo (Figura 2A), verificouse pelo questionário aplicado antes da atividade que os alunos associavam o solo com o plantio (50\%) e que uma boa parte dos alunos (36\%) não souberam responder a esta questão. Mesmo após a atividade, a utilização do solo para o plantio foi predominante nas respostas $(55,5 \%)$, porém foram citadas outras funções dentre elas, o fornecimento de materiais para a construção, artesanato e a sua ação como filtro da água (Figura 2B).

O solo é um recurso natural que desempenha muitas funções tanto nos ecossistemas agrícolas, como nos urbanos. Embora a sua importância como meio para a prática da atividade agrícola seja a predominante é necessário maior divulgação da sua importância em relação à água, biodiversidade e ao ar. A relação que os alunos fazem do solo com a agricultura expressa pelos resultados, pode ser explicada pelo material didático utilizado para o ensino de solo nas escolas, pois traduzem a percepção de que o solo é importante apenas para a produção agrícola, distanciando da realidade de muitos estudantes que vivem nas áreas urbanas (Vezzani, 2014).
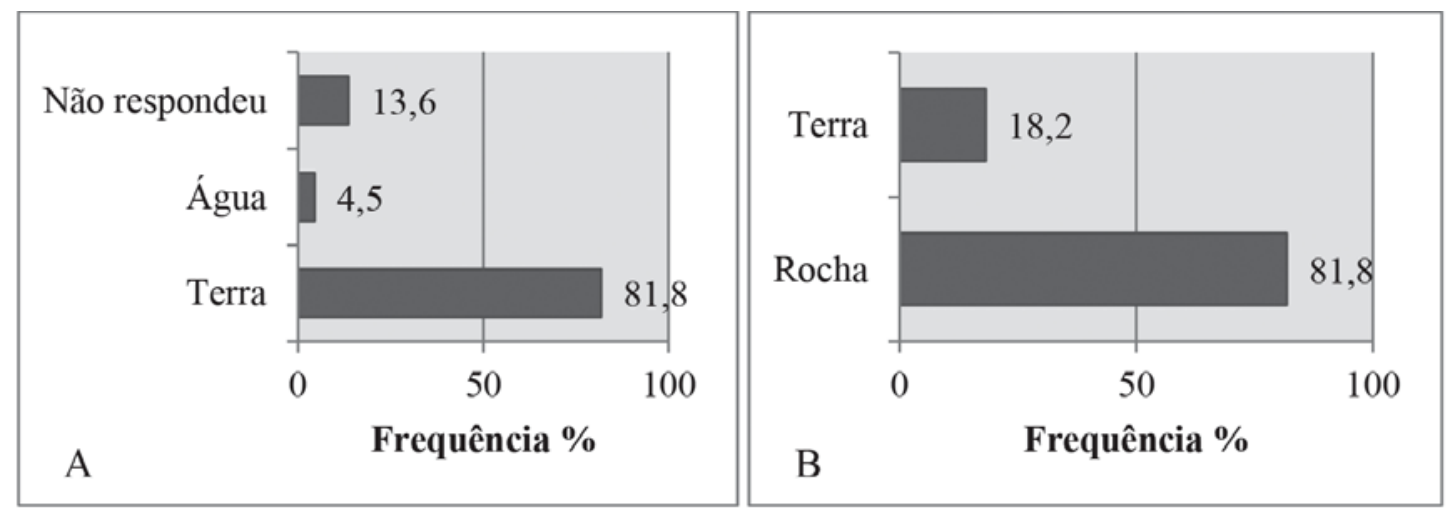

Figura 1 - O solo vem da? 
Os resultados encontrados neste trabalho corroboram os encontrados por Freitas et al. (2018), onde estes verificaram antes da realização de atividades com alunos do $5^{\circ}$ ano, que $28 \%$ deles associava o uso do solo para pisar, andar e passear, 7\% não souberam responder e $23 \%$ responderam que o solo serve para plantar. Após as atividades, o uso agrícola do solo prevaleceu com $41 \%$ das respostas, mas os alunos identificaram outros usos anteriormente não mencionados, como a construção civil (32\%) e os demais artesanato e pintura.

Os professores (biologia/ciências e geografia) do $6^{\circ}$ e $9^{\circ}$ ano do ensino fundamental, de uma escola da rede privada de ensino, na zona Oeste do Rio de Janeiro, citaram o uso do solo, como um dos temas relacionados a geociências mais problemáticos em termos de aprendizagem, justificando essa dificuldade por serem temas mais abstratos e falta de interesse no conteúdo (Bezerra et al., 2018).

O solo é constituído pela parte mineral (argila, areia, silte), a água, ar e a matéria orgânica que corresponde a resíduos em diferentes estágios de decomposição. Os organismos do solo (microrganismos, microfauna, mesofauna e macrofauna) são parte constituinte da matéria orgânica viva do solo. Quanto à questão que se referia à composição do solo (Figura $3 \mathrm{~A}), 23,8 \%$ dos alunos respondeu que este é composto por terra, $23,8 \%$ por formigas e minhocas, $14,3 \%$ areia e $23,8 \%$ não responderam.

A composição do solo mostrou-se como um tema que necessita ser trabalhado. Mesmo após a atividade, embora tenha sido explicada a composição do solo, os estudantes responderam que o solo é composto por animais $(53,8 \%)$ e houve aqueles que citaram alguns animais do solo (Figura 3B). Contudo a parte mineralógica não foi mencionada pelos alunos após a atividade. Mas verificou-se que foi citada a água como componente do solo $(11,5 \%)$ posterior a atividade. Assim, supõese que houve uma maior dificuldade por parte dos estudantes de entender esse conteúdo e a atividade não foi tão efetiva nesse sentido.

No trabalho realizado por Canapelle et al. (2018) apenas $16 \%$ conseguiram observar que solo é constituído pelas partes sólida, líquida e gasosa e $81 \%$ responderam ter conhecimentos dos animais que habitam o solo.

Freitas et al. (2018) também encontraram resultados semelhantes, ao questionar os alunos do $5^{\circ}$ ano sobre as principais diferenças que eles observavam no solo, em que $31 \%$ dos entrevistados não sabiam se existiam diferenças, $20 \%$ optaram em responder que não observam ou que não existe nenhuma diferença e os $48 \%$ restantes conseguiram identificar as diferentes características existentes no solo, como o relevo, areia, barro, umidade, texturas, cor, natureza, pedras, entre outras. Em contrapartida, após a realização de palestras e oficinas, $76 \%$ dos alunos conseguiram identificar as principais diferenças entre os solos.

Quanto às cores do solo, antes da atividade 38\% dos alunos respondeu que o solo tem cor marrom e $33,3 \%$ dos alunos não responderam (Figura 4A). Durante a atividade foi demonstrado amostras de solos de diferentes cores e durante a formação do perfil do solo, enfatizou-se as diferentes cores do solo. Após a atividade $42,9 \%$ dos alunos responderam que o solo apresenta várias cores e 10,7\% citaram que o solo tem a cor amarela, vermelha, marrom e preta (Figura 4B).

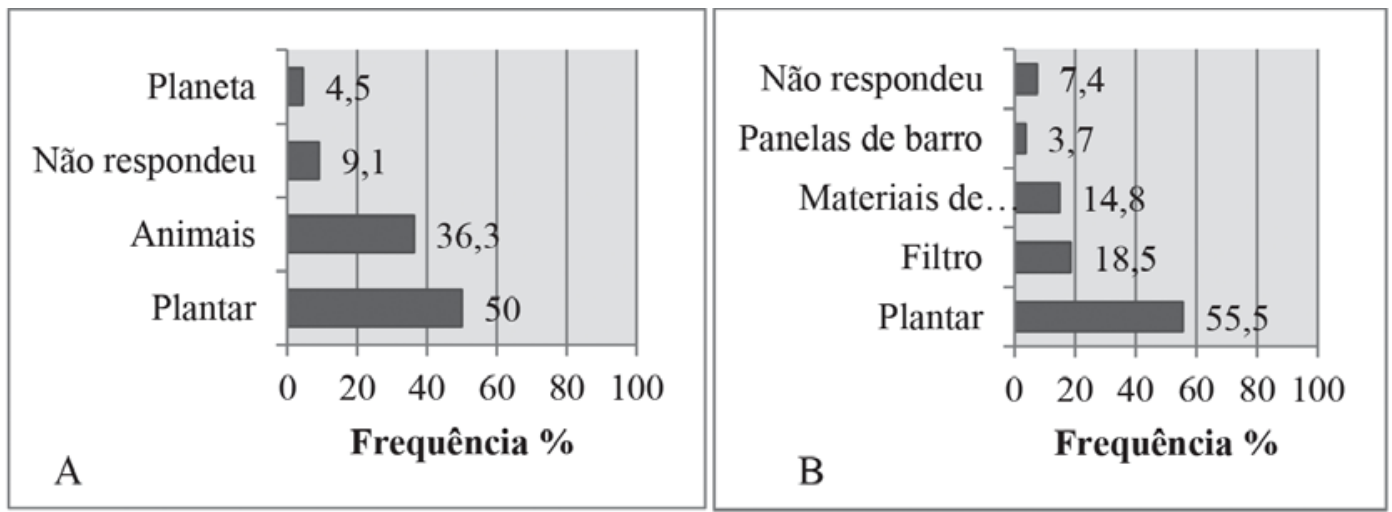

Figura 2 - O solo serve para? 

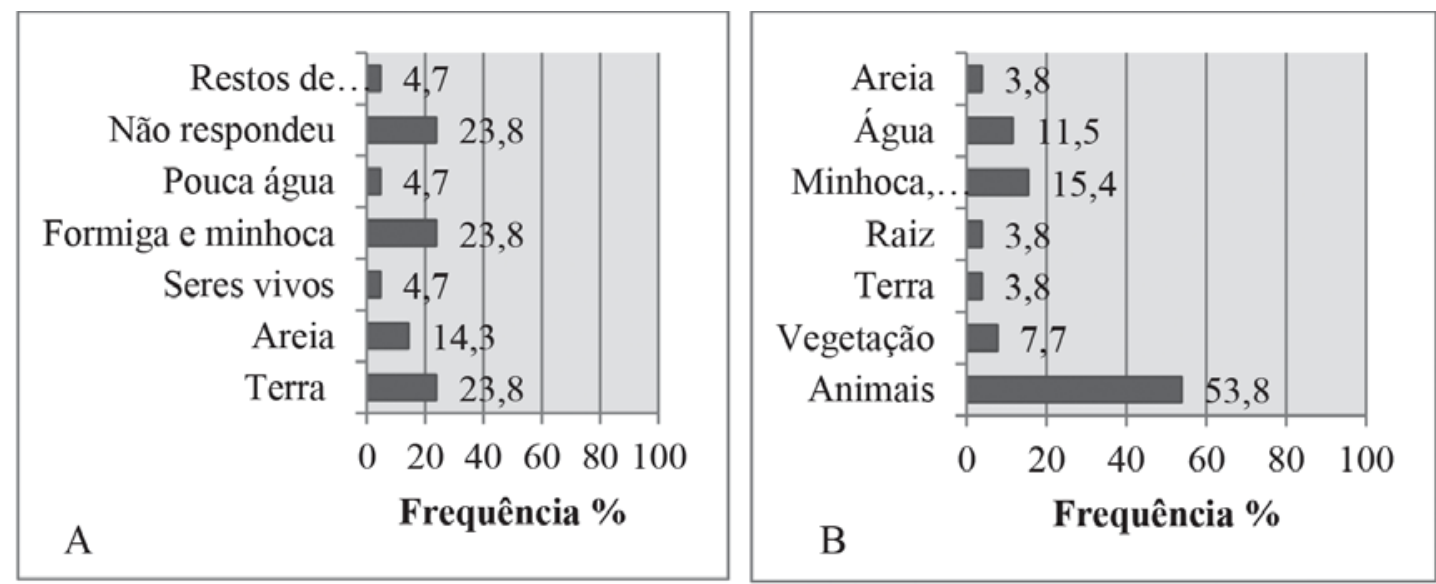

Figura 3 - No solo tem?
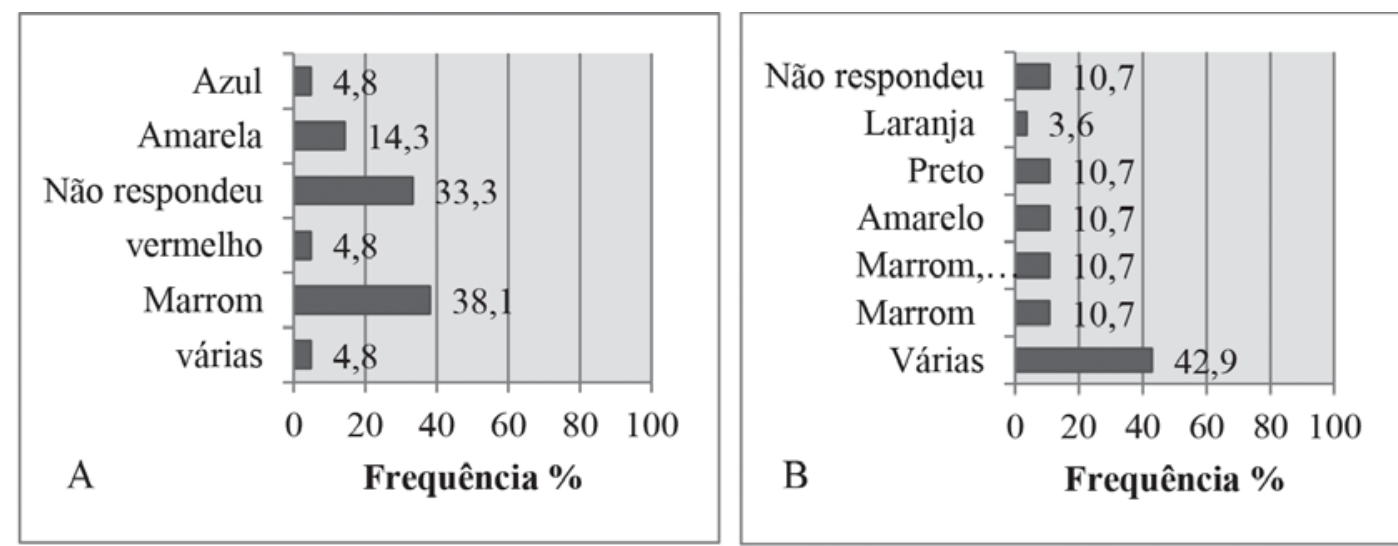

Figura 4 - O solo tem a cor?

A ação de extensão foi eficiente para explicar aos alunos que os solos apresentam várias cores. Houve uma parte dos alunos que citou a cor preta, marrom, vermelha e amarela como sendo as cores do solo, isso poderá ter sido induzido pela montagem do perfil do solo, uma vez que o perfil utilizado apresentava essas cores.

Um dos temas também abordados na ação foi a degradação do solo, e após a atividade foi avaliado o conhecimento dos alunos sobre isso (Figura 5). As ações que degradam o solo mais citadas foram a erosão (25\%), o desmatamento $(21,4 \%)$ e as queimadas $(21,4 \%)$.

A atividade foi importante para divulgar as ações que podem levar a degradação do solo, visto que esse é considerado um recurso natural não renovável e que deve ser conservado. Em relação à degradação do solo, a poluição foi menos citada pelos alunos e é um tema que precisa ser trabalhado, especificando tanto a poluição de origem urbana principalmente pelo lixo que é jogado no solo, bem como da rural pelo uso de agrotóxicos na agricultura.

Vale ressaltar também que a degradação do solo deve ser trabalhada relacionando as suas consequências para a qualidade da água e do ar. A queimada é um dos problemas mais frequentes nessa região e é importante que os alunos como futuros agentes da sociedade tenham consciência disso, uma vez que não é apenas o solo o afetado, mas também o ar, a água, biodiversidade e o clima devido a emissão dos gases efeito estufa.

A queimada e o desmatamento acabam acelerando o processo de erosão, que é um grave problema ambiental, que pode ocasionar danos a produção de alimentos 
pela diminuição da fertilidade do solo, da capacidade de retenção de água no solo e assoreamento de rios e lagos (Frasson \& Werlang, 2010).

Canapelle et al. (2018) constataram que a maioria dos estudantes (80\%), responderam que a principal forma de degradação do solo é a erosão causada pela chuva, trabalhando com alunos do ensino médio e fundamental. Os mesmos autores, enfatizaram a importância de trabalhar todas as formas de erosão, a laminar, em sulcos e voçorocas, pois os alunos associam a erosão mais com as voçorocas.

Freitas et al. (2018) perguntaram o que destrói o solo para alunos do $5^{\circ}$ ano e $30 \%$ não souberam responder absolutamente nada, enquanto $24 \%$ citaram a palavra poluição, $7 \%$ desmatamento e a chuva, aproximadamente $4 \%$ relataram fogo e $5 \%$ os seres humanos, antes de realizar palestras e oficinas com os alunos.

Quanto à atividade em si, 40,9\% dos alunos responderam que gostaram de aprender sobre tudo, mas foram citadas também ação do solo como filtro da água $(18,2 \%)$ e erosão $(18,2 \%)$, sendo essas duas relacionadas com os experimentos realizados (Figura 6). Os experimentos foram de extrema importância para que os alunos pudessem entender o funcionamento do solo.

A maior parte dos alunos responderam que ainda não tinham estudado sobre o solo (57\%), o que pode estar relacionado ao ano na qual se encontravam não englobar assuntos relacionados ao solo ou na época em que a ação foi realizada não tinham estudado sobre o solo (Figura 7).

De acordo com Silva e Santos (2016) para que seja possível aumentar, ou até mesmo despertar o interesse dos alunos pelo tema solos, se faz necessária a utilização de ferramentas práticas, como saídas de campo, experimentos ou usos dos recursos visuais onde os alunos possam interagir juntamente com o professor.

A utilização de experimentos facilitou a relação ensino-aprendizagem, trazendo para o plano concreto conceitos e conteúdos (Perusi \& De Sena, 2012). A falta de experimentos ou a falta de estímulo prévio pelo docente que também pode não ter muita afinidade quanto ao tema composição do solo, poderá explicar o porque de os alunos não conseguirem distinguir as partes constituintes do solo.

Os experimentos foram importantes para despertar mais a atenção dos alunos e facilitou muito a participação deles. Segundo Perusi \& De Sena (2012), que realizaram minicurso sobre o tema solo como um recurso natural, para 12 professores da rede pública de ensino, observaram que uma das principais dificuldades dos professores é inerente ao conteúdo de pedologia: fatores

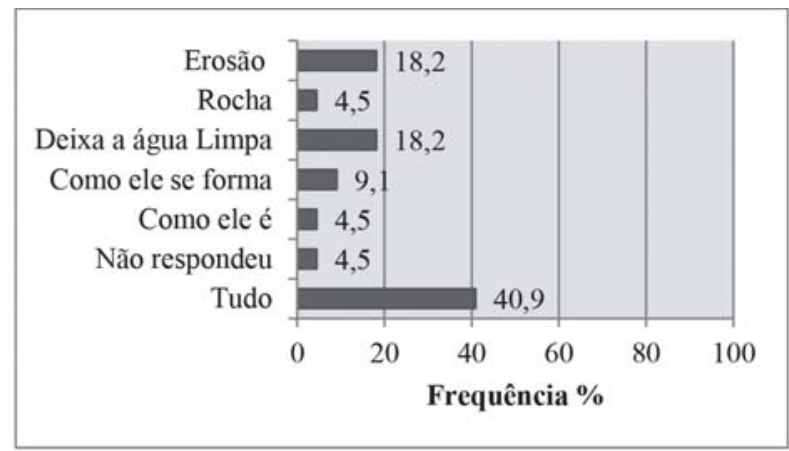

Figura 6 - O que mais gostaste de aprender?

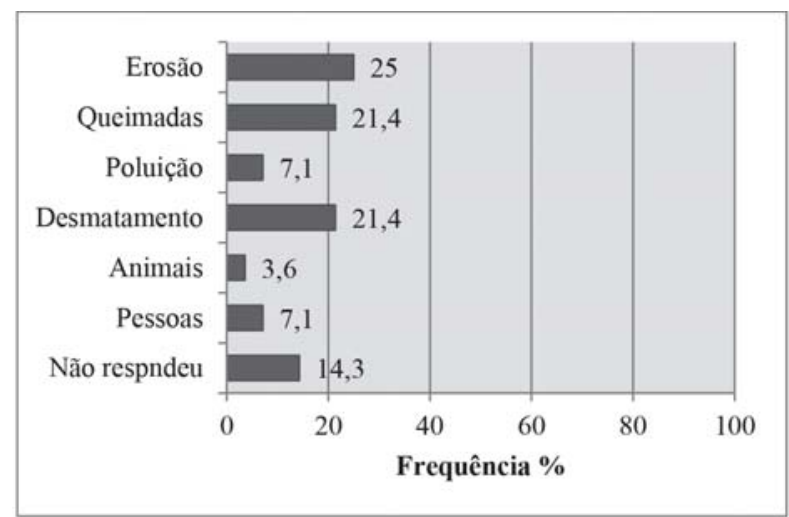

Figura 5 - O solo é degradado por?

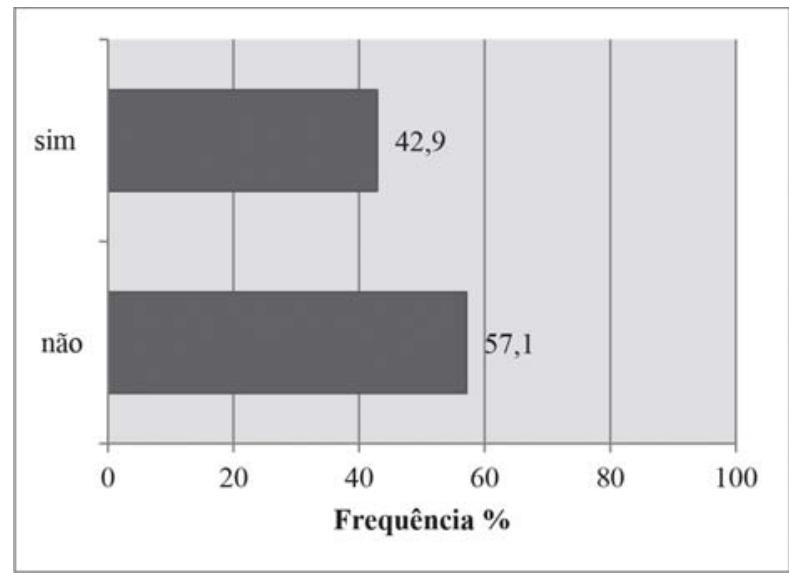

Figura 7 - Já estudou sobre o solo? 
e processos de formação do solo, composição geral do solo e, principais causas de degradação do solo.

De acordo com Canapelle et al. (2018), as escolas não possuem material didático adequado sobre tema solo, pois geralmente os livros didáticos de geografia e biologia apresentam informações resumidas ou superficiais sobre o tema solo, dificultando assim com que esse tema seja trabalhado de forma mais aprofundada.

Falcão (2011) avaliou o desempenho de alunos do $6^{\circ}$ ano de escola pública do município de Sobral, Estado do Ceará após atividades práticas e constatou que essas aumentavam o interesse e conhecimento dos alunos, sendo este progressivo.

Campos et al. (2012), em estudo realizado em quatro escolas do município de Humaitá, Amazonas, com turmas do $5^{\circ}$ ano, avaliaram a inserção do tema solo na concepção dos alunos sobre o meio ambiente. Para tal, foram realizadas oficinas sobre infiltração e retenção de água, porosidade, consistência, coleção de cores, composição e suas diferentes texturas do solo, a erosão e condomínio de minhocas. Após a realização das práticas, foi possível constatarem que, através de avaliações feitas com os alunos antes e depois das oficinas, que estes passaram a inserir o conceito de solo em suas concepções de meio ambiente.

Barros et al. (2017) realizaram oficinas teóricas e práticas com alunos do $5^{\circ}$ ano e verificaram que a parte teórica foi o que despertou menos interesse por parte deles. A oficina prática foi a que despertou maior interesse, com destaque para as práticas de infiltração e retenção de água no solo, porosidade do solo, composição do solo e as suas texturas.

A metodologia utilizada como avaliação, o questionário, teve como pontos negativos a dificuldade dos estudantes com a escrita que pode ser atribuída à faixa etária. A mesma dificuldade foi relatada por Comin et al. (2013) trabalhando com alunos do quarto ano do ensino fundamental.

Vale ressaltar que o processo de aprendizagem é uma via de mão dupla, onde, segundo Jesus (2013) primeiro o estudante deve ter disposição para aprender, enquanto a segunda, que o conhecimento a ser aprendido seja potencialmente significativo para esse aluno. Ressalta-se portanto, a criação e a aplicação de metodologias de ensino que promovam maior interação entre os estudantes no processo de ensino e principalmente para estudantes de zonas urbanas, procurar meios de ensino do solo de forma que esses percebam a importância do solo, além da prática agrícola.

\section{CONCLUSÕES}

Este trabalho ressaltou a importância de aliar experimentos com a teoria para o ensino de solos no ensino fundamental, estimulando dessa forma os alunos a aprender e a relacionar com a vivência dos mesmos. Assim, os alunos podem ver o solo sob outra perspectiva, para além daquela relacionada com a produção agrícola bem como com a parte ambiental.

Verificou-se que o conhecimento dos alunos antes da ação de extensão era incipiente e apresentavam deficiências principalmente com a formação deste recurso natural e sua utilização pelo homem, além da produção de alimentos. Porém, o entendimento da importância do solo pelos alunos, ficou evidenciada pelo segundo questionário, o que é relevante para a preservação deste recurso.

Constatou-se principalmente pela literatura citada e os resultados alcançados a importância da atualização dos materiais didáticos utilizados ou um reforço por parte dos professores quanto ao ensino de solo nas escolas.

\section{LITERATURACITADA}

BARDIN, L. Análise de Conteúdo. 2011. $1^{\text {a }}$ reimpressão da $1^{\text {a }}$ edição. Editora 70 . São Paulo SP. BRASIL. Ministério da Educação.1999.

Parâmetros Curriculares Nacionais ensino médio: ciências da natureza, matemática e outras tecnologias. Brasília: Secretaria de educação Média e Tecnológica.

BARROS, W.N. et al. Percepção de solos: experiência com estudantes do $5^{\circ}$ ano do Ensino Fundamental em escola de rede pública de Humaitá, AM. Revista da Universidade do Vale do Rio Verde, Três corações, v.15, n.2, p.558-565, ago/Dez, 2017.

BIONDI, D. Arborização urbana aplicada à educação ambiental nas escolas. Curitiba: Daniela Biondi, 2008. 120p.

BEZERRA, H.P.A; FIRMINO, A.R.S.; BARBOSA, J.R.A.; RODRIGUES, A.P.C. A informática e o ensino de geociências: estudo de caso em uma escola privada na zona oeste do Rio de Janeiro. Geosaberes, v.9, n.17, p.1-15, 2018. 
CAMPOS, M.C.C.; NETO, N.M.S.M.; VERAS, E.S.; SOUZA, Z.G.E.F. Percepção ambiental: experiência em escolas de ensino fundamental em Humaitá (AM). Ambiência, v.8, n.1, p.35-46, 2012.

COMIN, F.V.; FURLAN, M.; FERRONY, H.M.; OLIVEIRA, A.L. O ensino de solos sob a perspectiva da educação ambiental: aplicação de experimentos para ensino e conscientização. RCA Revista Científica da Ajes, v.4, n.9, 2013.

CANEPELLE, E.; KERKHOFF, J.T.; WRITZL, T.C.; STEIN, J.E.S.; SILVA, D.M.; REDIN, M. Ciência do solo nas escolas de ensino fundamental e médio. Revista Brasileira de Agropecuária Sustentável (RBAS), v.8, n.3, p.41-50, 2018

FALCÃO, C.L.C.; SOBRINHO, J.F.; ALVES, M.J.L. Discutindo o solo na escola do informativo didático da aprendizagem à arte da cor. Revista Homem, Espaço e Tempo, Universidade Estadual Vale do Acaraú - UVA, p.99-110, 2011.

FALCÃO, C.L.C.; SOBRINHO, J.F. A utilização de recursos didáticos como auxiliares no processo de aprendizagem do solo. Revista da Casa de Geografia de Sobral, v.16, n.1, p.19-28, 2014.

FRASSON, V.R.; WERLANG, M.K. Ensino de solos na perspectiva da educação ambiental: contribuições da ciência geográfica. Geografia: ensino e pesquisa, v.14, n.1, p.94-99, 2010.

FREITAS, A.L.; VITAL, A.F.M.; NASCIMENTO, B.M.S.; LUSTOSA, M.A.F.S.; SOUZA, M.P.S.; RAMOS, G.G. Percepções sobre a importância do solo: Estudo de caso em uma escola de Itapetim PE. Agropecuária Científica no Semiárido (ACSA), v.14, n.1, p.42-49, Janeiro-Março, 2018.

JESUS, O.S.F. et al. O vídeo didático "Conhecendo o Solo" e a contribuição desse recurso audiovisual no processo de aprendizagem no ensino fundamental. Revista Brasileira de Ciência do Solo, v.37, n.2, p.548-553, 2013.

LIMA, M.R. Extensão universitária em meio ambiente e sustentabilidade. Revista Brasileira de Extensão Universitária, v.2, n.2, p.63-120, 2004.
MUGGLER, C.C.; PINTO SOBRINHO, F.A.; MACHADO, V.A. Educação em solos: princípios, teoria e métodos. Revista Brasileira de Ciência do Solo, v.30, n.4, 2006.

OLIVEIRA, D. O conceito de solo sob o olhar de crianças do ensino fundamental em Escolas de São Paulo. Ciência e Natura, v.36, Ed especial, p.210214, 2014.

OLIVEIRA, D. Práticas didáticas de ensino, pesquisa, cultura e extensão universitária no Parque Cientec-USP: o projeto solo na escola-geografiaUSP. Revista Graduação USP, v.2, n.3, dez, 2017.

PÉREZ, D.V.; BREFIN, M.L.M.; POLIDORO, J.C. Solo, da origem da vida ao alicerce das civilizações: uso, manejo e gestão. Pesquisa Agropecuária Brasileira, v.51, n.9, p.1-4, 2016.

PERUSI, M.C.; DE SENA, C.C.R.G. Educação em solos, educação ambiental inclusiva e formação continuada de professores: múltiplos aspectos do saber geográfico. Entre Lugar, v.3, n.6, p.153-164, 2012.

SILVA, M.B.; SANTOS, A.C.R.L.C. A importância de aulas práticas para o ensino de solos na educação fundamental. In: SIMPÓSIO BRASILEIRO DE EDUCAÇÃO EM SOLOS, 8., 2016. São Paulo. Anais... São Paulo: Humanitas, p.294-299, 2016.

RIBEIRO, S.C.; MACÊDO, F.R.B. Conhecimentos prévios de solos de estudantes do ensino fundamental da zona rural do Cariri Cearense. In: SIMPÓSIO BRASILEIRO DE EDUCAÇÃO EM SOLOS, 8., 2016. São Paulo. Anais... São Paulo: Humanitas, p.250-254, 2016.

UFPR. Departamento de Solos e Engenharia Agrícola. Projeto solo na escola: experimentoteca de solos. Curitiba: UFPR, 2005.

VEZZANI, F.M. Valorização ambiental do solo. In: LIMA, M.R. (Org). Conhecendo os solos: abordagem para educadores do ensino fundamental na modalidade à distância. Curitiba: UFPR, 2014, 167p.

Recebido para publicação em 05/03/2019 e aprovado em 29/06/2019. 